\title{
Religion and Attitudes Toward Intimate Partner Violence: A Cross-National Study
}

\author{
Yang Yang ${ }^{1}$
}

yyyeehazel@gmail.com

\begin{abstract}
In a world where violence against women remains pervasive and serious, intimate partner violence (IPV) is one of the most common and harmful forms of violence against women. Since religion and religiosity have been found to be influential in shaping people's attitudes toward IPV, this global-scale study investigates the net effects of religion and religiosity on attitudes toward IPV with country-specific influences controlled. Using the data from the World Values Survey conducted between 2017 and 2020 that had 69,578 respondents with Ordinary Least Square regression (OLS) models, this study finds that being religious is related to less accepting attitudes toward IPV, while the frequency of attending religious activities does not have a statistically significant relationship with attitudes toward IPV. Variations in attitudes are found among different religious denominations as well. People belonging to some religious denominations show more acceptance of IPV, so the nuanced differences among specific religions are crucial in creating discrepancies in attitudes across religious people. The results call for more future interdisciplinary and mix-method research to further our understanding of the religious impact on attitudes toward IPV and to promote gender equality globally.
\end{abstract}

Keywords: intimate partner violence (IPV); religion; religiosity; attitudes; gender equality

\footnotetext{
${ }^{1}$ I would like to thank my supervisor Dr. Min Zhou, my family, and my friends for their continuous help, support, motivation, and guidance along the way of finishing this research. I am also grateful to be a recipient of a Jamie Cassels Undergraduate Research Award for this project. This research is the pinnacle of my undergraduate journey, and I will forever be grateful.
} 


\section{Religion and Attitudes Toward Intimate Partner Violence: A Cross-National Study}

How we think of intimate partner violence (IPV) remains significant as IPV is harmful to the wellbeing of many women (Wencheko \& Tadesse, 2020, World Health Organization [WHO], 2012); therefore, research can help to show what influences those attitudes to pave the way for better policy guidance. Religion, with its established power, is considered to be one of the factors that influences people's attitude toward gender (Perales \& Bouma, 2019). Extant sociology research on the relationship between religious people's practices, beliefs, and community involvement (religiosity) (Renzetti et al., 2017) and their attitudes toward gender has resulted in ambiguous findings. Some findings show that religions uphold patriarchy while others find that religions uphold harmonious family relationships. (Ellison et al., 1999; Mikolajczak \& Pietrzak, 2014, Perales \& Bouma, 2019, Wencheko \& Tadesse, 2020). At the same time, specific connections among religion, religiosity, and attitudes toward IPV have not been thoroughly examined. With such ambiguity and inconclusiveness, this research aims at examining the nuanced and specific relationship among religion, religiosity, and people's attitudes toward IPV beginning with this research question: what effects (positive or negative) do religion and religiosity have on people's attitudes toward IPV on a global scale? With the intention to better understand the contemporary impact of religion on people's attitudes toward a public health issue and its further societal influence, this research bears sociological significance and offers the foundation for more interdisciplinary research around this issue.

\section{Background}

Research on violence against women remains very relevant today. Violence against women is defined as a type of gender-based violence that all women and girls around the world are subject to (United Nations, 2015). Different types of violence against women include various degrees of physical, sexual, and psychological abuse, threats, and coercion, ranging from domestic violence, child marriage, and forced pregnancy that occurs in the family to femicide, honour killing, and female genital mutilation perpetrated by non-partners (United Nations, 2015).

Among these different types of violence, IPV is "one of the most common forms of violence against women and includes physical, sexual, and emotional abuse and controlling behaviour by an intimate partner" (WHO, 2012, p. 1). The high occurrence rate of IPV has been noted by sociological researchers and international institutions, both as a public health issue and a social determinant of health (SDOH) that directly impacts women (Interiano et al., 2018). According to a study conducted by WHO on women's health and domestic violence against women (2012), 13$61 \%$ of more than 24,000 women in 10 countries reported ever having experienced physical violence by a partner; $4-49 \%$ reported the physical violence being severe; 6-59\% reported sexual violence by a partner; and $20-75 \%$ reported experiencing some emotional abuses from a partner during lifetime.

IPV is found to be traumatic and debilitating and should be considered a public health problem (Ellison et al., 1999; Wencheko \& Tadesse, 2020). Not only can it affect women's physical health directly, but it can also lead to chronic mental and physical problems due to constant stress (WHO, 2012). Even after years of the occurrence of violence, women who were abused are twice likely to report poor health conditions as those who were not, and they also suffer from higher levels of depression and anxiety, which could further result in alcohol and drug abuse, self-harm behaviours, or even suicide (Ellison et al., 1999; WHO, 2012). For women who reside 
in societies where leaving their husbands is difficult, their help-seeking avenues are to some extent blocked as well (United Nations, 2015). Among various types of IPV, wife-beating is one of the most obvious signs of explicit physical violence, and it is often justified in many cultures (United Nations, 2015; Wencheko \& Tadesse, 2020). For instance, wife-beating in Zimbabwe is accepted as a social norm and is practiced to settle marital disputes (Wencheko \& Tadesse, 2020). Such acceptance also creates societal barriers that prevent women from talking about their experiences and leads to an unfriendly environment for the victims (United Nations, 2015).

The pervasiveness of IPV and its severe consequences cause concern on the path to gender equality. Since IPV in part stems from the patriarchal system that creates power imbalances between men and women, people's attitude to IPV can be in line with their overall gender attitudes (Perales \& Bouma, 2019). Men who are loyal supporters of patriarchal society expect themselves to be the breadwinners and expect their wives to submit to them (Perales \& Bouma, 2019). When these expectations are not fulfilled, they may be frustrated and become violent (Perales \& Bouma, 2019). Therefore, it can be predicted that people with more egalitarian gender attitudes would have lower acceptance of IPV (Perales \& Bouma, 2019). Also, researchers have found that people who are more likely to think IPV can be justified are also more likely to become the perpetrators than those who do not (United Nations, 2015). Therefore, to further promote gender equality and to reduce the occurrence of IPV, it is critical to find out what socio-demographic characteristics foster or prevent more egalitarian gender attitudes so that actions can be taken to lower people's acceptance of IPV.

Religion and religiosity are found to be among the most influential socio-demographic characteristics that have strong impacts on people's gender attitudes (Perales \& Bouma, 2019; Schnabel, 2015). A classic and succinct definition of religion is the "belief in spiritual beings" (Tylor, 1970, as cited in de Muckadell, 2014). Religiosity, according to Renzetti et al. (2017), can be divided into three dimensions: practice, the "outward, observable expressions of faith" (p.1977); belief, the "personal framings and meanings" of religion (p.1977); and communities, the "involvement and relationships grounded in a congregation or religious group" (p.1977). The potential connection of religion with attitudes toward IPV stems from the inseparable relationship between religions and gender-stereotypical tendencies (Perales \& Bouma, 2019), and as the relationship between religion and gender-based violence has gained some attention, how religions and religiosity are related to specific attitudes toward IPV needs to be more closely examined (Ellison et al., 1999; Wencheko \& Tadesse, 2020).

Current research has found religion to be both directly and indirectly associated with sexism because stereotypical gender views and even broader patriarchal values are incorporated into religious authorities (Mikolajczak \& Pietrzak, 2014). In Mikolajczak and Pietrzak's findings, religion is a way for people to organize, understand, and employ their values, while religiosity is found to be linked with values that breed attachment to the status quo and traditions that eventually lead to sustaining the patriarchal social norms and presumed gender roles (2014). Religious teachings from their holy books are understandably patriarchal: Religions like Christianity have male God figures with most of their scriptures more or less considered as patriarchal in contemporary society (Perales \& Bouma, 2019). Those who believe that these teachings are inerrant are more likely to fully embrace these values (Ellison et al., 2019).

On the other hand, there is also evidence that religion and religious practices have a preventing impact on the acceptance and perpetration of IPV (Ellison et al., 1999). Within some religious books, there are contents that promote devotion to families (Ellison et al., 1999). It can be inferred that this commitment to families is embedded into religious activities and teachings, 
from sermons to everyday social interactions through reading these books. Religious congregations are also found to promote committed relationships and family life as a means to achieve personal and spiritual growth (Ellison et al., 1999). Under such influence, people are more likely to endorse their assigned family roles and take on their responsibilities in the families in order to show their devotedness and piousness, to the extent that they would be eager to resolve possible conflicts instead of resorting to violence for solutions (Ellison et al., 1999). It is noteworthy that the relationship between such religious teaching and actual harmonious familial relationship is not causative, it just points out a possible correlation and demonstrates the possibility of influence of religious teachings on people's implicit attitudes.

Given the two distinctly opposite roles religion and religiosity may play in relation to people's attitudes toward IPV, it is necessary to conduct an empirical analysis of the effects of religion and religiosity on said attitudes. Current research is mainly focused on single countries, and the ones that studied many countries were focused on gender attitudes instead of specific attitudes toward IPV (Seguino, 2011). Therefore, this research is intended to fill the gap and use data on 48 countries and regions to help produce a more global and thorough understanding of the subject matter.

\section{Literature Review and Hypotheses}

Many studies have found religious involvement to have a negative impact on gender equality and a strong association with patriarchal attitudes (Ellison et al., 1999; Jung \& Olson, 2017; Mikołajczak \& Pietrzak, 2014; Perales \& Bouma, 2019; Schnabel, 2015; Seguino, 2011). Formal religious institutions were found to have a strong impact on cultural norms and individual behaviours, which include the rigidity of gender attitudes (Inglehart \& Norris, 2003, as cited in Seguino, 2011). Although no religion explicitly sanctions violence against women on the surface, some people may be especially prone to violence against their spouses when they belong to a conservative religious denomination (religious denomination is used as synonymous with religious groups in the World Values Survey [WVS]) (Ellison et al. 1999). Researchers have found that the impact of religion and religiosity on gender attitudes could lead to macro-level gender inequality around the world, which also lines up with individual-level relationships between religion and gender attitudes (Mikołajczak \& Pietrzak, 2014). Seguino's study (2011) using data from the WVS revealed that non-religious people have the least patriarchal attitudes and those who consider religion to be an important part of their lives and attend religious services more often indicate more discriminative attitudes toward women.

Despite the burgeoning evidence in support of the negative effect of religion on attitudes toward IPV, some studies have found that religious practices are related to positive marriage outcomes because religious teachings promote family values and self-sacrifice, support committed relationships, and provide solutions to marital conflicts through religious seminars and pastoral counselling (Ellison et al. 1999; Jung \& Olson, 2017). This attention to harmonious families means that religiosity may lead to less accepting attitudes toward IPV, as religious teachings often involve the sanctity of marriage and condemnation of IPV, which allow members with high religiosity to not accept IPV as much as those with low religiosity (Jung \& Olson, 2017).

How do people from different religious denominations differ in their gender attitudes and attitudes toward IPV? Many scholars have conducted research to understand the potential differences across various religions (Brooks \& Bolzendahl, 2004; Perales \& Bouma, 2019; Seguino, 2011; Wencheko \& Tadesse, 2020). In these studies, although some differences across 
religions were found (e.g., Evangelical and Black Protestants reported more patriarchal gender attitudes than Catholics; Brooks \& Bolzendahl, 2004), more researchers found that there were no significant differences in patriarchal gender attitudes across major religions (Seguino, 2011). Since Seguino's research (2011) is also cross-national (given a fixed effect for countries), similar to this study, and also used WVS data (used different waves as dummy variables), it is speculated that the difference in attitudes toward IPV may not significantly differ across religious groups.

Since differences in attitude toward IPV in different religions are uncommonly found in current literature, it is necessary for researchers to consider the reason behind it and examine whether a different result can be found if more variables are controlled. Many religions are global, meaning that there are people who believe in the same religion and belong to the same religious denominations across the world, but it is not a guarantee that they have the same attitudes when it comes to the level of IPV acceptance (Minkov \& Hofstede, 2014). Researchers have found that not all differences found across religious groups can be viewed as religious differences because environmental, geographical, and cultural differences also generate these differences (Minkov \& Hofstede, 2014). What Minkov and Hofstede (2014) discovered is that nations have a "gravitational" effect on people's cultural values, and global religions, on the contrary, do not have such an effect.

This national effect reveals how people who belong to different religious denominations but live in the same nation are similar to one another, and they are distinguishable from other religions in other nations (Minkov \& Hofstede, 2014). Global religions, however, do not have control over their different branches in different nations, so people do not share the same values even if they belong to the same religious denominations (Minkov \& Hofstede, 2014). What is salient here is that religious differences are hard to determine as other socioeconomic, sociodemographic, geographical, and cultural factors are often at play that can also influence people's values. Therefore, it is necessary for us to control for the country variable to explore whether findings in the current literature hold true.

Besides religion and religiosity, many other factors can influence people's gender attitudes and attitudes toward IPV (Seguino, 2011; Wang, 2016). Research has revealed that education is one of the most significant protective predictors of attitudes toward IPV as people with higher education manifest lower acceptance of IPV (Gracis \& Tomás, 2014; Seguino, 2011; Wang, 2016). Meanwhile, men are found to be holding significantly more unequal gender attitudes than women, so it is predicted that men will be more accepting of IPV (Seguino, 2011). Younger people and people with lower socioeconomic status are more accepting of IPV as well (Wang, 2016; Wencheko \& Tadesse, 2020). These factors are included as control variables because of their established confounding effects.

Given the ambiguity and inconclusiveness regarding the effect of religion and religiosity on attitudes toward IPV in the existing literature, it is necessary to further explore this subject matter through a cross-national analysis. Therefore, my research question is, "What effects (positive or negative) do religion and religiosity have on people's attitudes toward IPV on a global scale?"

Five hypotheses are proposed to guide the analysis. As described above, the existing literature is contested and suggests two opposite influences of religion on attitudes toward IPV. The first and the second hypotheses are competing hypotheses based on the contested literature. This research tries to adjudicate this debate in the existing literature. Three variables are used to measure religion: being religious, the frequency of attending religious activities, and specific religious denominations. The third hypothesis is mainly to re-examine Seguino's finding (2011) 
that there are no major differences across major religious denominations in their effects on attitudes toward IPV.

Hypothesis 1-1 (H1-1; being religious or not/religion as a whole): Those who are religious are more likely to think IPV is justifiable.

Hypothesis 1-2 (H1-2; being religious or not/religion as a whole): Those who are religious are less accepting of IPV.

Hypothesis 2-1 (H2-1; religiosity): As one attends religious activities more often, the attitudes toward IPV are more accepting.

Hypothesis 2-2 (H2-1; religiosity): As one attends religious activities more often, the attitudes toward IPV are less accepting.

Hypothesis 3 (H3; differences among specific religions): There are no significant differences in the acceptance of IPV across different religious denominations.

\section{Data and Method}

The dataset used in this research is Wave 7 of the WVS conducted between 2017 and 2020. The dataset includes 69,578 individuals from 48 countries and regions and therefore offers large and recent data to generate meaningful results (Inglehart et al., 2020). The WVS is a global research project carried out by social scientists exploring people's values and beliefs, including their changes over time and their social and political impact on the societies (Inglehart et al., 2020). The questionnaire has questions for all variables used in my analysis. The first round of sampling selected a national representative random sample, which is followed by a second-round simple probability sampling for people aged 18 and older (Inglehart et al., 2020). Despite nuances that exist for each country, requirements for high representativeness are the same for all countries, as the number of samples in each country is in proportion with their respective population (Inglehart et al., 2020).

Multivariate regression analysis is used for the data analysis, specifically, ordinary least squares (OLS) regression through the software package STATA (version16) to analyze the data. OLS regression is commonly used to analyze a continuous dependent variable through a linear regression model while controlling other key variables. It is suitable for this research as the dependent variable, the acceptance of IPV, is measured by this question "whether it is justifiable for a man to beat his wife" on a 10-point scale ( $1=$ never justifiable, $10=$ always justifiable), which can be treated as a continuous variable.

The main independent variables of interest are being religious, religiosity, and specific religious denominations. Being religious (or religion as a whole) for Hypothesis 1 is measured by this question: "Independently of whether you attend religious services or not, would you say you are: 1. A religious person, 2. Not a religious person, 3. An atheist"? Option 2 and 3 are combined as "non-religious" and make this variable binary (being religious as 1 and non-religious as 0 ). Religiosity in Hypothesis 2 is measured by the question "Apart from weddings and funerals, about how often do you attend religious services these days?" on a 7-point scale $(1=$ more than once a week, $7=$ never) and is treated as a continuous variable. The coding is reversed into $1=$ never, $7=$ more than once a week. This measurement of religiosity captures the practice dimension introduced by Renzetti et al. (2017). Different religious denominations in Hypothesis 3 are measured by the question "Do you belong to a religion or religious denomination? If yes, which one?" In this specific research, the scope of religions is restricted to the religious groups used in the questionnaire of the WVS Wave 7. In addition, age (measured in years), gender (measured by 
the respondent's sex observed by the interviewer) ${ }^{2}$; educational levels ("the highest educational level the respondent has attained" on a 9-point scale); marital status, including the married, divorced and separated, widowed, and single (never married) categories; and household income (self-reported on a 10-point scale) are controlled. Finally, since the current literature has revealed the necessity to control for country variables that have influences on people's values to determine the net effect of religions (Minkov \& Hofstede, 2014), countries are controlled by a set of dummy variables representing individual countries and regions.

\section{Descriptive Statistics}

\section{Results}

Table 1 shows the descriptive information of the variables. The other tables present the regression models that examine the hypotheses. Overall, the empirical evidence supports H1-2 and partly supports $\mathrm{H} 2-1$ but does not support $\mathrm{H} 3$.

\section{Table 1}

Descriptive Statistics $(N=69578)$

\begin{tabular}{llll}
\hline & & Frequency & Percentage \\
\hline Gender & Women (reference) & 36478 & 52.47 \\
Religious or not & Men & 33049 & 47.53 \\
& Religious & 43809 & 64.58 \\
Religion or religious & Not religious (reference) & 24028 & 35.42 \\
denomination & Do not belong to a & 15186 & 22.08 \\
& denomination (reference) & & \\
& Roman Catholic & 13111 & 19.06 \\
& Protestant & 4090 & 5.95 \\
& Orthodox (Russian, Greek, & 5747 & 8.35 \\
& etc.) & & \\
& Jew & 132 & 0.19 \\
& Muslim & 21017 & 30.55 \\
& Hindu & 382 & 0.56 \\
& Buddhist & 4363 & 6.34 \\
& Other Christian & 2893 & 4.21 \\
& (Evangelical, Pentecostal, & & \\
& Free Church, etc.) & & \\
& Other & 1866 & 2.71 \\
& Married (reference) & 44742 & 64.62 \\
Divorced and separated & 4295 & 6.2 \\
Widowed & 3858 & 5.57 \\
& Single & 16348 & 23.61
\end{tabular}

\footnotetext{
${ }^{2}$ Please note that gender identity is not the same as sex. WVS uses observed sex to represent gender and it might not be fully accurate in recording perceived gender identities of the participants. It is a limitation of the survey worth noticing.
} 


\begin{tabular}{llll}
\hline & & & \\
& & Mean & SD \\
Religiosity & Religiosity on a 7-point & 4.047 & 2.166 \\
& scale & & \\
Age & Age from 16 to 103 & 42.586 & 16.279 \\
Education & Education on a 9-point & 3.414 & 2.028 \\
Household income & Scale & & \\
\hline
\end{tabular}

\section{Being Religious and Attitudes Toward IPV}

Table 2 presents the first four models that discuss the relationship between a person being religious or not and their attitudes toward IPV. The first model only includes these two variables, and the result shows that people who are religious score slightly higher than those who are not religious (by 0.000582 points) in the acceptance of IPV. This difference is not statistically significant. After adding in gender, education, age, income, and marital status, the coefficient of being religious turns negative, which means that being religious shows a protective effect on people's attitude toward IPV after adding these demographic and socioeconomic characteristics. Furthermore, this effect becomes statistically significant when the country variable is controlled.

Table 2

Being Religious and Attitudes Toward IPV

\begin{tabular}{lllll}
\hline & Model 1 & Model 2 & Model 3 & Model 4 \\
\hline Intercept & $1.816^{* *}$ & $2.347^{* *}$ & $2.417^{* *}$ & $1.631^{* *}$ \\
Religious & 0.00058 & -0.0191 & -0.0261 & $-0.0506^{* *}$ \\
Women & & $-0.183^{* *}$ & $-0.193^{* *}$ & $-0.175^{* *}$ \\
Education & & $-0.062^{* *}$ & $-0.059^{* *}$ & $-0.056^{* *}$ \\
Age & $-0.007^{* *}$ & $-0.008^{* *}$ & $-0.004^{* *}$ \\
Income & $0.016^{* *}$ & $0.016^{* *}$ & $0.017^{* *}$ \\
Marital status (married & & & \\
as reference) & & & \\
$\quad$ & & $-0.080^{* *}$ & 0.008 \\
$\quad$ Divorced/separated & & & $0.127^{* *}$ & $0.068^{*}$ \\
$\quad$ Sidowed & & $-0.069^{* *}$ & -0.005 \\
Country and region & & & Controlled \\
Adjusted $\mathrm{R}^{2}$ & & & 0.0097 & 0.0788 \\
\hline Note. ${ }^{*} \mathrm{p}<0.05, * * \mathrm{p}<0.01$. Countries and regions are only controlled in the last model.
\end{tabular}

As expected, education serves as a protective factor in relation to attitudes toward IPV: As one's education level increases by one level, they score around 0.06 points lower on the IPV acceptance scale. Gender difference is as anticipated: Women are less accepting of IPV than men by around 0.18 points. Both these control variables remain significant throughout all the models, even when the country variables are controlled. It means that the protective effect of education and women's lower acceptance hold around the globe. The incorporation of quadratic term of age is run in the software, and its effect is found to be not significant, so it is not included in the models 
presented here. When only the variable age itself is used, the coefficient reveals that as one's age increases, they would be less accepting of IPV. Although this result contradicts the empirical analysis of Seguino (2011), which shows that younger people are less likely to hold inequitable gender attitudes, it can be explained by the recklessness of young age (WHO, 2012).

Income shows a trend different from that suggested by the current literature. As one's income level increases, they are more likely to think that IPV can be justified, which is contrary to current findings (Seguino, 2011; Wang, 2016), which conclude that higher income is an indicator for more equitable gender attitudes and thus leads to less acceptance of IPV. This finding probably indicates that people who are better off financially are more inclined to support the status quo and the patriarchal system embedded in society. From Model 3, it is obvious that divorced and separated people and single people show less acceptance than married people $(0.08$ points and 0.068 points lower, respectively), while widowed people score 0.126 points higher on the scale than married people. This difference changes when the country variables are controlled, as now only widowed people score 0.068 points higher than married people while the difference among married people and the other two groups becomes insignificant.

Adjusted $\mathrm{R}^{2}$ in a regression model is an indicator that measures how well the model fits the data. It represents the proportion of the variance in a dependent variable that can be explained by all independent variables in a regression model. In these regression models, one can see that the adjusted $\mathrm{R}^{2}$ steadily increases from Model 1 to Model 4 (from 0 to 0.0788 ), which means that the model fits the data better with more control variables added. Although the increase is small from Model 1 to Model 3 (from close to 0 to 0.0097), the increase from Model 3 to Model 4 is worth noting (from 0.0097 to 0.0788 ). This large increase indicates that the country variables greatly improve the fit of the regression model, so the variations among countries should be considered and controlled in the model.

\section{Religiosity and Attitudes Toward IPV}

The results of the relationship between religiosity and attitudes toward IPV are shown in Table 3. Although religiosity is shown to be significantly related to one's attitudes toward IPV from Model 1 to Model 3, this relationship ceases to be significant when the country variables are controlled. From Model 1 to Model 3, the coefficient of religiosity is positive, indicating that as one attends religious activities more often, they are more likely to think that IPV is justifiable.

Table 3

Religiosity and Attitudes Toward IPV

\begin{tabular}{lllll}
\hline & Model 1 & Model 2 & Model 3 & Model 4 \\
\hline Intercept & $1.712^{* *}$ & $2.252^{* *}$ & $2.317^{* *}$ & $1.600^{* *}$ \\
Religiosity & $0.026^{* *}$ & $0.015^{* *}$ & $0.015^{* *}$ & 0.004 \\
Women & & $-0.183^{* *}$ & $-0.193^{* *}$ & $-0.180^{* *}$ \\
Education & & $-0.059^{* *}$ & $-0.057^{* *}$ & $-0.004^{* *}$ \\
Age & & $-0.007^{* *}$ & $-0.008^{* *}$ & $0.0026^{* *}$ \\
Income & $0.016^{* *}$ & $0.015^{* *}$ & $0.017^{* *}$ \\
Marital status (married as & & & & \\
reference) & & & \\
$\quad$ Divorced/separated & & & $-0.073^{*}$ & 0.011 \\
\hline
\end{tabular}




\begin{tabular}{|c|c|c|c|c|}
\hline Widowed & & & $0.136 * *$ & $0.081 *$ \\
\hline Single & & & $-0.006 * *$ & 0.0004 \\
\hline Country and region & & & & Controlled \\
\hline Adjusted $\mathrm{R}^{2}$ & 0.0010 & 0.0096 & 0.0100 & 0.0797 \\
\hline
\end{tabular}

However, the increase in the acceptance of IPV is not very noticeable, and as more control variables are added to the analysis, the increase gradually decreases. In Model 1, as one's religiosity increases by one level, their score on the justifiability scale would increase by 0.0262 points, but in Model 3 this increase is only 0.0148 per level. In Model 4 where the country variables are controlled, this small increase becomes insignificant, indicating that from a global perspective, religiosity does not significantly affect people's attitudes toward IPV.

Gender and education as control variables remain significant throughout the four models. Women always score lower on the scale than men, and education is always a protective factor: Those with more education are less likely to justify IPV. As one's age increases, they also show less acceptance toward IPV, which contradicts with Seguino's findings (2011) that older people are more likely to hold inequitable gender attitudes due to their higher exposure to more organized religions. However, it is in accordance with the empirical evidence for Hypothesis 1. As religious people are less accepting of IPV, older people who are more likely to be religious are more prone to maintaining traditional and harmonious families that refrain from using violence. People with higher income, on the other hand, are more accepting of IPV, contrary to the current literature (Seguino, 2011; Wang, 2016). Marital status remains a less significant demographic variable, as only widowed individuals significantly score higher than married individuals. Similarly, the adjusted $\mathrm{R}^{2}$ experiences a large increase from Model 3 to Model 4 (from 0.0100 to 0.0797), indicating the importance of controlling the country variables in the regression model.

\section{Different Religions and Attitudes Toward IPV}

Table 4, Table 5, and Figure 1 explore the differences in attitudes toward IPV among people who are from different religious denominations. Although in the current literature, no religious denomination is found to be associated with more inequitable gender attitudes, and only a few denominations are found to be significantly different from those who are not religious (Seguino, 2011), the results presented in the tables and Figure 1 show otherwise. Therefore, Hypothesis 3 is not supported by the empirical results here. 
Table 4

Different religions and the attitudes toward IPV

\begin{tabular}{|c|c|c|c|c|}
\hline & Model 1 & Model 2 & Model 3 & Model 4 \\
\hline Intercept & $1.742 * *$ & $2.211 * *$ & $2.255^{* *}$ & $1.628 * *$ \\
\hline \multicolumn{5}{|l|}{$\begin{array}{l}\text { Religion or religious } \\
\text { denomination (do not } \\
\text { belong as reference) }\end{array}$} \\
\hline Roman Catholic & 0.013 & 0.002 & -0.002 & $-0.059 *$ \\
\hline Protestant & $-0.150 * *$ & $-0.172 * *$ & $-0.172 * *$ & $-0.087 *$ \\
\hline Orthodox & -0.018 & -0.026 & -0.037 & $-0.229 * *$ \\
\hline Jew & 0.266 & 0.164 & 0.162 & 0.252 \\
\hline Muslim & $0.269 * *$ & $0.208 * *$ & $0.199 * *$ & $0.147 * *$ \\
\hline Hindu & $0.388 * *$ & $0.343 * *$ & $0.338 * *$ & $0.274 * *$ \\
\hline Buddhist & $0.146 * *$ & $0.112 * *$ & $0.111 * *$ & 0.004 \\
\hline Other Christian & $-0.079 *$ & -0.063 & -0.061 & $-0.117 * *$ \\
\hline Other & $-0.188 * *$ & $-0.182 * *$ & $-0.182 * *$ & -0.061 \\
\hline Women & & $-0.184 * *$ & $-0.193 * *$ & $-0.179 * *$ \\
\hline Education & & $-0.053 * *$ & $-0.052 * *$ & $-0.055 * *$ \\
\hline Age & & $-0.006 * *$ & $-0.007 * *$ & $-0.004 * *$ \\
\hline Income & & $0.014 * *$ & $0.014 * *$ & $0.017 * *$ \\
\hline \multicolumn{5}{|c|}{$\begin{array}{l}\text { Marital status (married as } \\
\text { reference) }\end{array}$} \\
\hline Divorced/separated & & & -0.018 & 0.011 \\
\hline Widowed & & & $0.142 * *$ & $0.086 * *$ \\
\hline Single & & & -0.032 & 0.002 \\
\hline Country and region & & & & Controlled \\
\hline Adjusted R² & 0.0062 & 0.0136 & 0.0138 & 0.0807 \\
\hline
\end{tabular}

When there are no other control variables, people from six out of nine religious denominations score significantly differently from those who are not religious. These differences remain when all control variables are added, although there are some changes in regard to which denominations are significantly higher or lower than non-religious people. Some denominations are not significantly different from non-religious people in the first model but are so in the last one, and some show the opposite trend. Roman Catholic and Orthodox belong to the first type, which indicates that country differences confound the effects of these two religious denominations on the attitudes toward IPV. When the country variables are controlled, both denominations score lower on the scale, showing less accepting attitudes than the non-religious group.

On the contrary, Buddhists and people from other denominations initially score differently from non-religious people, with Buddhists scoring higher and people from other denominations scoring lower than non-religious people in the first model, but both differences cease to be significant when the country variables are controlled. This indicates that although people from these denominations may have statistically significant different attitudes from non-religious people on the surface, this disparity in attitudes does not hold when countries are controlled, and the potential influence of countries is eliminated. From the significance levels and signs of the 
coefficients in the last model, one can see that people in Roman Catholic, Protestant, Orthodox, and Other Christian denominations are less likely to justify IPV than non-religious people, while people who are Muslim and Hindu are more likely to justify IPV. Jewish people and Buddhists do not significantly differ from non-religious people in terms of attitudes toward IPV when all control variables are included.

Additional statistical tests are employed based on Model 4 of Table 4 to further explore the differences across different religious denominations, whose results are shown in Table 5. Contrary to the current literature, variations are found among many denominations with only a few exceptions: Only 15 out of 36 comparisons across denominations remain insignificant in Model 4, indicating that differences in attitudes toward IPV exist across the majority of denominations and that their specific religious teachings and practices could lead to different attitudes.

Figure 1 shows the average score people from different religious denominations have on the justifiability scale. On average, it seems that Jewish, Muslim, and Hindu people score significantly higher on the scale than non-religious people, among which Hindu people score the highest. But it is noteworthy that in Model 4 of Table 4, Jewish people do not score significantly differently from non-religious people. It is possible that the small sample size of Jewish people in the data (i.e., only 132 people in the data identify themselves as Jewish) leads to the insignificant difference. The results for Muslim and Hindu people align with Model 4. People who belong to Orthodox religions, on the other hand, score the lowest on average, which is also in accordance with its coefficient in Model 4 of Table 4.

\section{Table 5}

\section{Differences Across Different Religions}

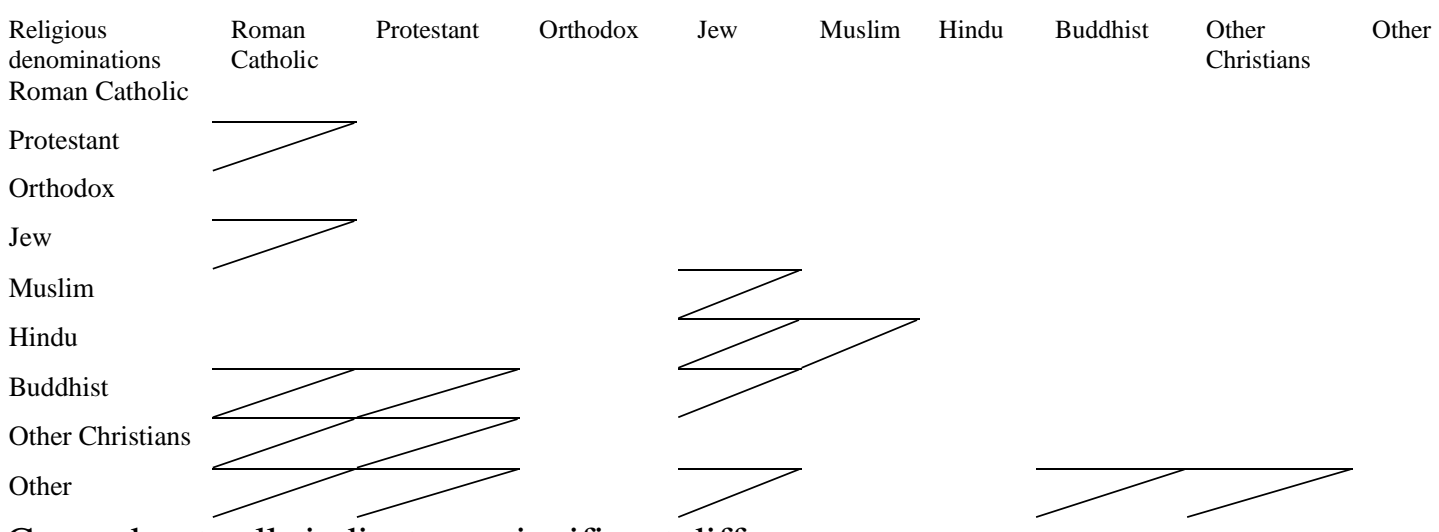

Note. Crossed-out cells indicate no significant differences. 


\section{Figure 1}

\section{Average Score on the IPV Justifiability Scale for Different Religious Denominations}

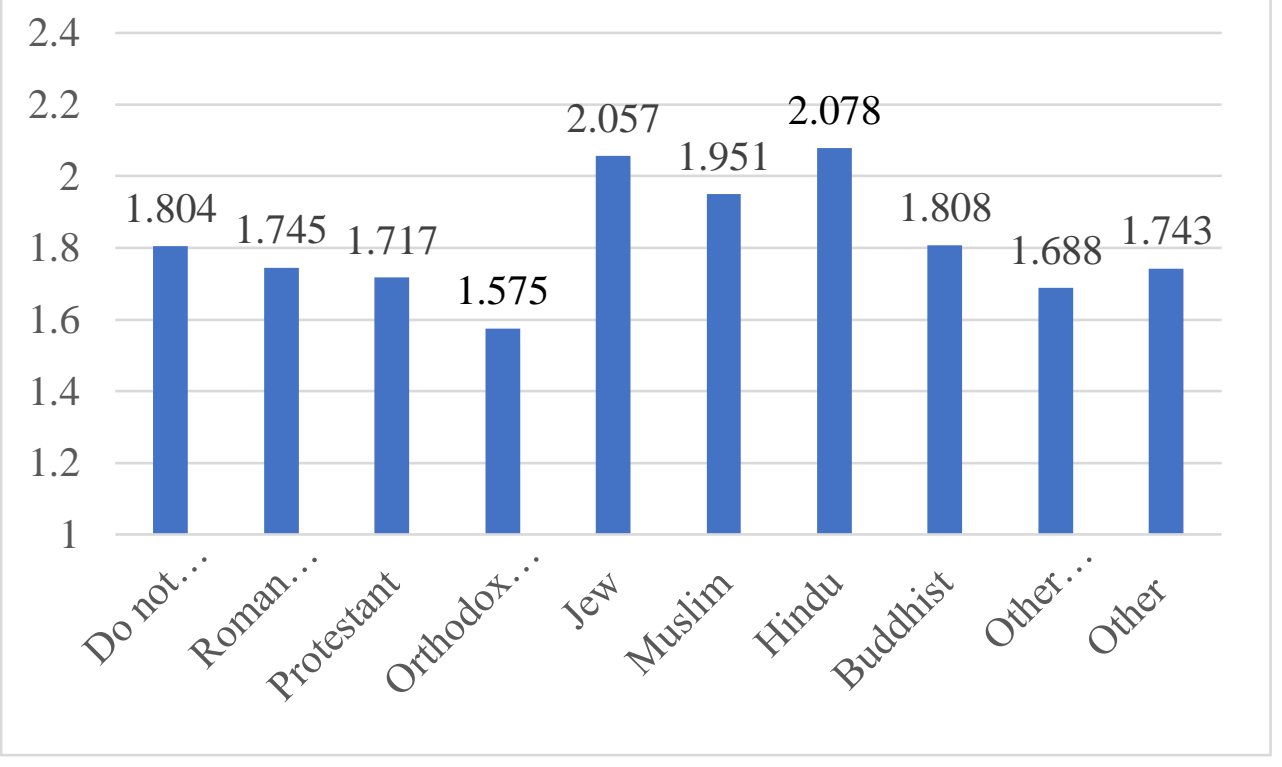

In summary, Hypothesis 1-2 and Hypothesis 2-1 (partly) are supported. More specifically, religious people overall have less accepting attitudes toward IPV than non-religious people. When the country variables are not controlled, higher religiosity is associated with a higher score on the justifiability scale, indicating that more frequent attendance at religious activities leads to more acceptance toward IPV. However, this significance ceases to exist when the country variables are controlled, so religiosity does not significantly impact people's attitudes toward IPV, strictly speaking. Simply put, it is being religious that has an impact on people's attitudes toward IPV, not their frequency of attending religious activities. Hypothesis 3, on the other hand, is not supported by the empirical evidence: Significant differences are found across most of the religious denominations, and most of the religious denominations are significantly different from nonreligious people.

It is noteworthy that people from some religious denominations score higher than nonreligious people, which seems to contradict the result of Hypothesis 1 . However, it can be inferred that compared with the first set of models that examines only the individual's overall identification with religion, the regression models in Table 4 that involve specific religious denominations address more nuances across different denominations. The variable of being religious cannot give us a clear idea of what religious denomination one belongs to, and different religious denominations may operate differently and yield various patriarchal gender attitudes that cannot be revealed by this general variable of being religious in the first set of models.

As for other variables, some are consistent with extant research, such as education and gender. Since people with higher education always show less accepting attitudes toward IPV, education serves as a protective factor against IPV (Wang, 2016). Women are found to be less accepting of IPV as well, which is in accordance with current empirical findings that show women are much less likely to embrace unequal gender attitudes (Gracis \& Tomás, 2014; Seguino, 2011). 
Older people exemplify lower acceptance of IPV, which is contrary to the global trend of gender equality that is more evident among younger individuals who are less exposed to formalized religious conditioning and unequal gender stereotypes with more women engaged in paid work (2011). People with higher income display higher acceptance toward IPV, which contradicts the current literature that tells us higher socioeconomic status reduces the risk of accepting IPV (Wang, 2016).

Since it is the country variables that cause a drastic change in the significance levels in all models, it can be inferred that different countries offer different social, cultural, and economic contexts under which religion has differing influences on people. The results presented here are generated after the elimination of the impact of different countries and regions, which increases the validity of the findings. In doing so, the results here are the net influence of different religions instead of being confounded by other national different characteristics.

\section{Limitations and Future Research}

As mentioned before, the measurement of religiosity in this study is insufficient according to Renzetti et al. (2017). Out of the three dimensions Renzetti et al. (2017) introduced, only practice, the "outward, observable expressions of faith" (p.1977), is captured and measured in the questionnaire. Belief and communities, the other two dimensions that capture the more nuanced attachment people have to their religions, are missing from the data. Such omission in the key definition of religiosity is therefore insufficient to explore the complete effect of religiosity on people's attitudes toward IPV. Also, same-sex IPV and transgender-specific IPV is not examined in this heterosexual-IPV analysis. Specific reasons behind these types of IPV require further attention and study. Meanwhile, as a quantitative study, this analysis lacks examination of personal interpretations of religious impact on their attitudes toward IPV, which calls for future mixedmethod approaches to analyze this subject matter more thoroughly. Lastly, future research needs to explore the relationship between attitudes and behaviours to better promote gender equality in practice, as attitudes do not necessarily lead to future violent behaviour.

\section{Discussion and Conclusion}

This study investigates the influence of religion and religiosity on people's attitudes toward IPV on a global scale. The current literature shows contradictory findings on the direction of this influence, and this study aims to adjudicate this debate using cross-national empirical data. It reveals that religious people are less likely than non-religious people to justify IPV when key socio-demographic characteristics and especially country-specific variables are controlled. Meanwhile, the frequency of attending religious activities does not have a statistically significant relationship with people's attitudes toward IPV, which means that it is the religious belief that creates the differences in acceptance, not the behaviours of attending religious activities. Differences across religious denominations are also found.

These results show that being religious has a protective effect against justifications of IPV in general, but the nuances across different religions require further and closer examination. It suggests that policies regarding uplifting women's status among religious denominations need to be precise as not all denominations yield the same negative impact. As Seguino (2011) points out, religions themselves are changing with the changing social climate. Denominations that are more 
accepting of IPV are predicted to shift their beliefs to embrace the future world. At the same time, as policy makers discuss the necessity of education, it is imperative to eradicate the obstacles that keep girls out of school. Similarly, their access to jobs needs to be legally guaranteed. Policy enforcement appears to be particularly crucial during the COVID-19 pandemic where many people have undergone challenges. In addition to better protection against education and career losses for women, those who are experiencing IPV and are trapped with their abusers need support more than ever. Policies regarding IPV need to be more responsive so that more people can be helped, especially during such a crisis.

To conclude, this study offers important insights into how religion and religiosity influence people's attitudes toward IPV using contemporary and large data with the intention to inform the public, religious leaders, and policy makers about the religious impact on people's attitudes toward a serious health issue. A good understanding of the social factors underlying people's attitudes toward IPV will help eliminate IPV and advance gender equality. More sociological research is needed to further improve the understanding of this topic. 


\section{References}

Brooks, C., \& Bolzendahl, C. (2004). The transformation of US gender role attitudes: Cohort replacement, social-structural change, and ideological learning. Social Science Research, $33.106-133$.

de Muckadell, C. S. (2014). On essentialism and real definitions of religion. Journal of the American Academy of Religion, 82(2). 495-520.

Ellison, G. C., Bartkowski, P, J., \& Anderson, L, K. (1999). Are there religious variations in domestic violence? Journal of Family Issues, 20. 87-113.

Gracis, E. \& Tomás, M. J. (2014). Correlates of victim-blaming attitudes regarding partner violence against women among the Spanish general population. Violence Against Women, 20(1). 26-41. https://doi.org/10.1177/1077801213520577

Inglehart, R., Haerpfer, C., Moreno, Welzel, C., Kizilova, K., Diez-Medrano, J., Lagos, M., Norris, P., Ponarin, E., \& Puranen, B., et al. (eds.). (2020). World Values Survey: Round Seven - Country-Pooled Datafile. JD Systems Institute https://www.worldvaluessurvey.org/WVSDocumentationWV7.jsp

Interiano, A., Keltner, C., Knoll, D., \& Sonnenshine, A. (2018). Addressing intimate partner violence as a social determinant of health in clinical settings. California IPV \& Health Policy Leadership Cohort. http://www.ochealthiertogether.org/content/sites/ochca/Local_Reports/OCWHP_Policy Brief_2018_Addressing_IPV_as_an_SDOH_in_Clinical_Settings.pdf.

Jung, H. J., \& Olson, V. A, D. (2017). Where does religion matter most? Personal religiosity and the acceptability of wife-beating in cross-national perspective. Sociological Inquiry, 87(4). 608-633. https://doi.org/10.1111/soin.12164

Mikołajczak, M., \& Pietrzak, J. (2014). Ambivalent sexism and religion: Connected through values. Sex Roles, 70. 387-299.

Minkov, M., \& Hofstede, G. (2014). National versus religious: Which has a stronger effect on societal values? Management International Review, 54. 801-824.

Perales, F., \& Bouma, G. (2019). Religion, religiosity and patriarchal gender beliefs: Understanding the Australian experience. Journal of Sociology, 55(2). 323-341. https://doi.org/10.1177/1440783318791755

Renzetti, M, C. DeWall, N, C., Messer, A., \& Pond, R. (2017). By the grace of god: Religiosity, religious self-regulation, and perpetration of intimate partner violence. Journal of Family Issues, 38(14). 1974-1997. 
Schnabel, L. (2015). Religion and gender equality worldwide: A country-level analysis. Social Indicators Research, 129. 893-907.

Seguino, S. (2011). Help or hindrance? Religion's impact on gender inequality in attitudes and outcomes. World Development, 39. 1308-1321.

United Nations Department of Economic and Social Affairs (2015).The World's Women 2015: Trends and Statistics. Retrieved from https://unstats.un.org/unsd/gender/downloads/worldswomen2015_report.pdf

Wang, L. L. (2016). Factors influencing attitude toward intimate partner violence. Aggression and Violent Behavior, 29. 72-78.

Wencheko, E., \& Tadesse, M. (2020). Determinants of Ethiopian women's attitudes toward wife beating. Journal of Interpersonal Violence, 35(1-2). 510-520.

World Health Organization. (2012). Understanding and Addressing Violence Against Women: Intimate Partner Violence (WHO/RHR/12.36). https://www.paho.org/hq/dmdocuments/2012/paho-violence-women-fs-ipv-2012.pdf 